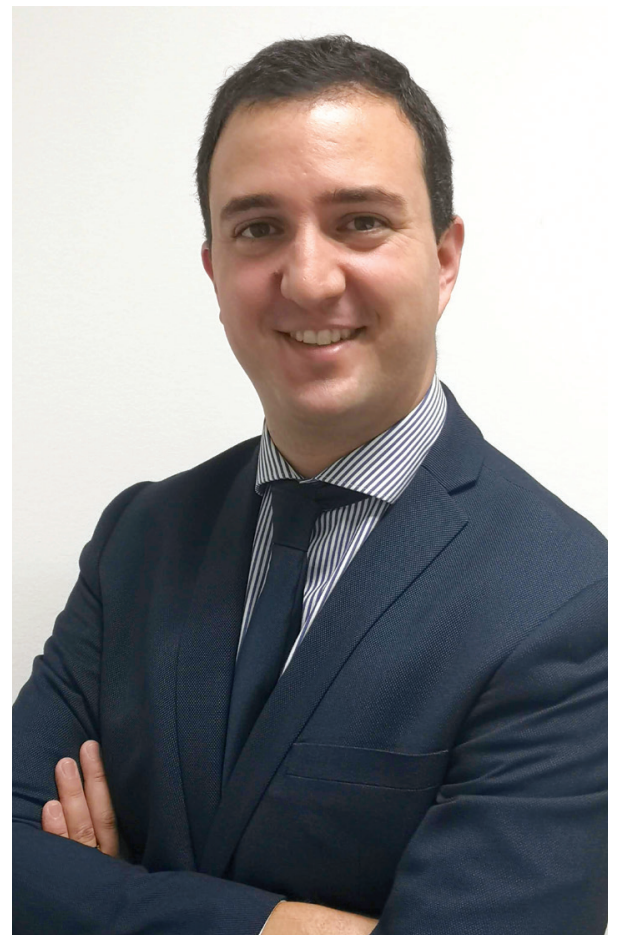

\title{
Valor em Saúde: Do Conceito à Implementação
}

\section{Value Based Healthcare: From the Concept to Implementation}

\author{
João Paulo Leal
}

\section{O CONCEITO DE VALUE BASED HEALTHCARE (VBH)}

A medição de valor em saúde tem sido tema nos últimos anos no setor. Este é um assunto premente não apenas pela necessidade de enquadrar inovação em saúde, conseguir quantificar investimentos versus resultados, mas acima de tudo por ser necessário que os cuidados sejam centrados no doente.

A definição formal de value based healthcare (VBH) surge do rácio entre os resultados em saúde relevantes para a qualidade de vida do doente e os custos associados ao ciclo de tratamento, necessários para obter esses resultados. É assim uma equação composta por indicadores reportados pelo cliente (PROMs - patient reported outcome measures), indicadores clínicos, indicadores de processo e custos.

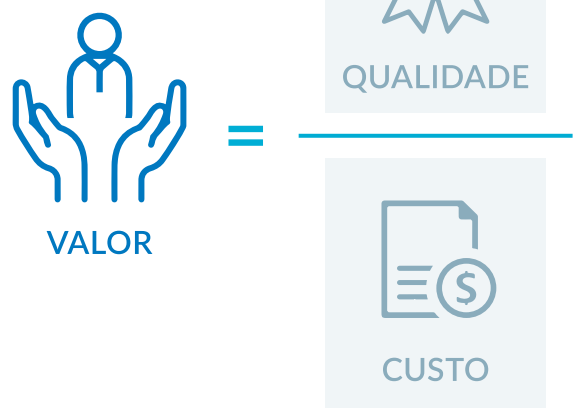

FIGURA 1. Equação de Valor em Saúde.
Dado que são analisadas estas quatro dimensões por cada patologia, num número de indicadores que seja compreensivo mas de interpretação facilitada, estamos perante uma ferramenta de gestão (scorecards) que permite sinalizar e realçar boas práticas. Este é o ponto zero para o que será um objetivo maior de comparabilidade e transversalização.

\section{O PAPEL DOS DIFERENTES STAKEHOLDERS}

Com a mudança de paradigma provocada pela implementação de estratégias de $\mathrm{VBH}$, os stakeholders em saúde deverão, mais do que nunca, olhar para o doente numa visão compreensiva e integrada. Hoje em dia, os cuidados ao doente requerem uma visão interligada de todos os pontos da cadeia de prestação de cuidados, in- 
cluindo fornecedores, pagadores, prestadores e o próprio doente. Os fornecedores caminham para a definição de métricas de qualidade de vida geral, considerando a satisfação do cliente, e incorporando esses resultados no seu produto. Relativamente aos acordos comerciais com pagadores, estes dirigem-se para uma lógica de value-based purchasing onde o risco financeiro dos tratamentos é partilhado com os prestadores e os fornecedores. Os prestadores detêm um papel fundamental na equação do VBH, uma vez que a gestão do modelo tradicional, focado no volume, se realinha assim para a obtenção de outcomes clínicos relevantes para o doente, a par de uma entrega de cuidados de excelência e uma visão de jornada de tratamento (clinical pathway). Por último, o doente vê-se incluído na tomada de decisão, num caminho que se pretende mais informado e mais inclusivo.

\section{O ICHOM E SUA EVOLUÇÃO}

O International Consortium for Health Outcomes Measurement (ICHOM) é uma organização que trabalha segundo a metodologia desenvolvida pelo Professor Michael E. Porter e por Elizabeth O. Teisberg em 2006 na Harvard Business School. O livro Redefining Health Care que ambos escreveram foi pioneiro na divulgação da utilização de outcomes clínicos para redefinir a natureza competitiva do mercado em saúde. A nível estratégico a organização conta com o apoio do Boston Consulting Group.

O ICHOM disponibiliza atualmente standard sets para 26 diferentes patologias, standard sets esses que remetem para um guia que estrutura a informação e timings de recolha de outcomes. Esta é uma particularidade bastante importante que alavanca a medição de valor em diferentes prestadores, até de diferentes países, de forma sistemática, possibilitando a comparação de resultados (devidamente ajustados ao risco e complexidade da população tratada).

Nos dias de hoje, o ICHOM estende ainda o seu raio de ação em duas áreas: implementação e benchmarking. É, no entanto, importante que o trabalho já desenvolvido seja mantido e que iniciativas como o GLOBE tenham a devida continuidade.

\section{O VBH NA JOSÉ DE MELLO SAÚDE}

O percurso do VBH na José de Mello Saúde (JMS) começou em 2016, com um projeto-piloto centrado, numa primeira fase, na Cirurgia da Catarata. No espaço de dois anos juntaram-se mais duas patologias - o Cancro da Mama e a Osteoartrose do Joelho - seguindo sempre uma lógica, ainda hoje mantida, de avançar para a monitorização de patologias de elevada casuística e/ou elevada diferenciação clínica, contando hoje em dia com 10 implementações bem-sucedidas (em seis unidades JMS).

Percebendo o potencial do VBH para a melhoria da prestação de cuidados de saúde, a José de Mello Saúde decidiu incluí-lo na definição estratégica 2017-2020, alinhado com o pilar do Projeto Clínico Diferenciador.

Um passo essencial nesta caminhada foi a criação do Advisory Clínico, liderado pelo Professor José Fragata e composto por médicos que são referência nas suas áreas de especialidade. Este grupo tem como missão a discussão e fomentação dos conceitos de Valor em Saúde, não deixando de fazer uma análise crítica à sua evolução interna e externa.

Apesar de toda a conceção feita à volta da definição anteriormente referida, foi para a José de Mello Saúde importante estabelecer o foco e âmbito do Programa no mote "Medir e Melhorar":

1. MEDIR - Definir e analisar os indicadores relevantes, tanto ao nível dos resultados como dos custos;

2. MELHORAR - Identificar oportunidades de melhoria e adotar soluções.

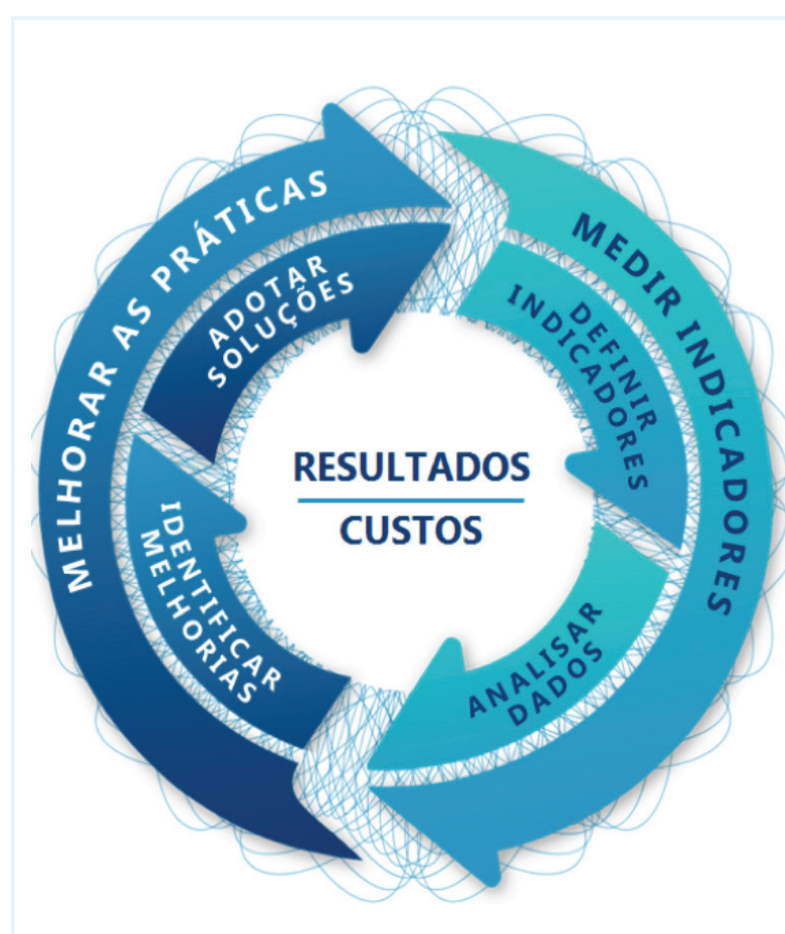

FIGURA 2. Ciclo e metodologia de VBH na José de Mello Saúde. 
Deixando para uma implementação a médio prazo a componente de custos, foi dada ênfase na primeira fase da metodologia: Medir. Esta exige um grande esforço técnico para garantir a existência de sistemas de registo e informação ajustados. Esta necessidade está a ser endereçada por diversos projetos da JMS, dos quais destaco:

- Portal de Gestão de Informação Clínica - agregador de plataformas de registo clínico;

- IAmetrics - Indicadores Clínicos com base em codificação clínica;

- SINAS, EUSOMA, ACSA - como bases para Indicadores de Processo;

- Projeto Data Warehouse (DWH) na componente de Business Intelligence Clínico para analisar variações e assinalar oportunidades de melhoria.

\section{O QUE FICA POR RESPONDER}

Não obstante da importância das metodologias apresentadas, é nosso pensamento que o conceito de VBH precisa de melhorias quando aplicado à prática clínica do dia-a-dia. Não é igual a interpretação destas metodologias para uma gestão populacional ou gestão de recursos em saúde (visão estratégica), quando comparada com uma visão ao doente (visão operacional). Será, por isso, importante manter o empenho na implementação do VBH em diferentes patologias, que seja feita a partilha de experiências através das conferências já existentes e que sejam publicados conteúdos.

O futuro do VBH e resposta a estas questões passa também pela colaboração entre entidades. É nesse sentido que a JMS tem vindo a trabalhar, sendo exemplo a recente aprovação do Laboratório Colaborativo Value4Health (CoLAB NOVA, JMS, Vodafone, Fraunhofer) e a colaboração no NOVA Institute for Value Improvement in Health and Care.

\section{CONVITE À PUBLICAÇÃO CIENTÍFICA COM BASE NO VBH}

Não podia deixar de aproveitar a oportunidade para convidar à participação da comunidade médica para que a temática de valor em saúde seja também foco da Gazeta Médica. A publicação na Sociedade Portuguesa de Oncologia feita com a Dra. Ida Negreiros (Responsável da UDTI da Mama - CUF Instituto de Oncologia) (Negreiro I, Leal J. 2017). Resultados Clínicos da Mama - O caminho para a medição de valor em saúde) é um primeiro exemplo que criou interesse e que estamos disponíveis para repetir.

"If you can't measure it, you can't improve it"

Peter Drucker

João Paulo Leal

Direção de Organização, Qualidade e Segurança - José de Mello Saúde 